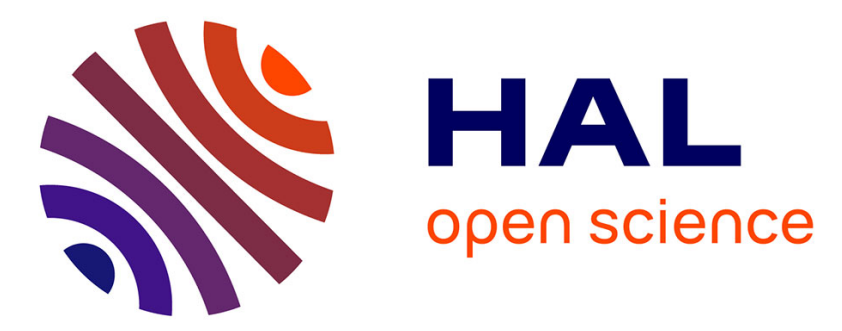

\title{
Compensatory immigration challenges predator control: An experimental evidence-based approach improves management
}

Nicolas Lieury, Sandrine Ruette, Sebastien Devillard, Michel Albaret, Franck Drouyer, Bruno Baudoux, Alexandre Millon

\section{To cite this version:}

Nicolas Lieury, Sandrine Ruette, Sebastien Devillard, Michel Albaret, Franck Drouyer, et al.. Compensatory immigration challenges predator control: An experimental evidence-based approach improves management. Journal of Wildlife Management, 2015, 79 (3), pp.425 - 434. 10.1002/jwmg.850 . hal03559057

\section{HAL Id: hal-03559057 \\ https: / hal-amu.archives-ouvertes.fr/hal-03559057}

Submitted on 5 Feb 2022

HAL is a multi-disciplinary open access archive for the deposit and dissemination of scientific research documents, whether they are published or not. The documents may come from teaching and research institutions in France or abroad, or from public or private research centers.
L'archive ouverte pluridisciplinaire HAL, est destinée au dépôt et à la diffusion de documents scientifiques de niveau recherche, publiés ou non, émanant des établissements d'enseignement et de recherche français ou étrangers, des laboratoires publics ou privés. 


\title{
Compensatory Immigration Challenges Predator Control: An Experimental Evidence-Based Approach Improves Management
}

\author{
NICOLAS LIEURY, Institut Méditerranéen de Biodiversité et d'Ecologie marine et continentale (IMBE), Aix Marseille Université, CNRS, IRD, \\ Avignon Université, Technopôle Arbois-Méditerranée, Bâtiment Villemin-BP 80, F-13545, Aix-en-Provence cedex 04, France \\ SANDRINE RUETTE, ${ }^{1}$ Office National de la Chasse et de la Faune Sauvage, CNERA Prédateurs Animaux Déprédateurs, Montfort, Birieux 01330, \\ France \\ SEBASTIEN DEVILLARD, Laboratoire de Biométrie et Biologie Evolutive, Université de Lyon, Université Lyon 1, CNRS, F-69000, Lyon \\ UMR5558, Villeurbanne F-69622, France \\ MICHEL ALBARET, Office National de la Chasse et de la Faune Sauvage, CNERA Prédateurs Animaux Déprédateurs, Montfort, Birieux 01330, \\ France \\ FRANCK DROUYER, Fédération départementale des chasseurs d'Ille-et-Vilaine, Maison de la Chasse, Beauregard, Saint-Symphorien 35630, France \\ BRUNO BAUDOUX, Fédération départementale des chasseurs de l'Aube, Maison de la Chasse, Chemin de la Queue de la Pelle, La Rivière de Corps \\ 10440, France \\ ALEXANDRE MILLON, Institut Méditerranéen de Biodiversité et d'Ecologie marine et continentale (IMBE), Aix-Marseille Université, CNRS, \\ IRD, Avignon Université, Technopôte Arbois-Méditerranée, Bätiment Villemin-BP 80, Aix-en-Provence cedex 04 F-13545, France
}

\begin{abstract}
Attempts to control predator numbers through spatially restricted culling typically faces a compensation process via immigration from surrounding source populations. To extend control effort to avoid this issue is in most instances impractical, both logistically and financially. Evidence-based strategy is therefore required to improve management practices. In close collaboration with local managers and hunters, we manipulated culling effort on red fox (Vulpes vulpes) over 5-6 years in 5 areas measuring $246 \pm 53 \mathrm{~km}^{2}$. We estimated fox density in late February each year by spotlight counts with distance sampling and estimated reproductive performance by post-mortem examination of culled foxes. We then used mixed modeling to assess how culling rate (defined as foxes killed/foxes available) affected fox population growth from year to year, accounting for compensatory feedbacks. We found a strong compensatory density feedback acting through immigration, allowing red fox populations to resist high culling rates. Culling appeared ineffective at reducing late winter densities to below $25-32 \%$ of the estimated carrying capacity. On average, an annual culling rate equivalent to about $45 \%$ of the pre-breeding population was required to maintain density at $1 \mathrm{fox} /$ $\mathrm{km}^{2}$, given a carrying capacity of $1.5 \mathrm{foxes} / \mathrm{km}^{2}$, although there was considerable variation among sites. The required culling rate dropped to $25 \%$ if the culling could be performed during winter, after the fox dispersal period. In contrast, culling during the pre-dispersal breeding period was totally compensated for through immigration by the following February. Concentrating culling during the winter could improve the ability of practitioners to control year-to-year trends in fox numbers, taking into account site-specific carrying capacity. A winter strategy would also reduce the number of animals killed and hence the ethical and logistical costs of fox control, given limited financial and human resources. Our study illustrates how collaboration between local practitioners and scientists can make large-scale replicated management experiments achievable, leading to mutually approved guidelines. (C) 2015 The Wildlife Society.
\end{abstract}

KEY WORDS carrying capacity, compensatory immigration, demographic compensation, density feedback, evidencebased management, mammalian carnivores, predator control, red fox, Vulpes vulpes.

Compensatory density feedback is the positive response of population growth to density reduction. This process is a cornerstone in both theoretical and applied population ecology (Herrando-Pérez et al. 2012). In a management

Received: 22 September 2014; Accepted: 7 January 2015

${ }^{1}$ E-mail: sandrine.ruette@oncfs.gouv.fr context, it renders the harvest of wildlife resources sustainable (Skalski et al. 2005). However, it also challenges the management of species considered as over-abundant, impairing the reduction of their impact on human activity (e.g., livestock farming, game hunting; Baker et al. 2007). The control of predators, alien or native, has recently become a popular tool for favoring species of conservation concern (Goodrich and Buskirk 1995). In the field however, 
practitioners often fail to reduce density, and the culling of a large number of individuals raises animal welfare concern (Baker et al. 2007).

The aggregated response of population growth rate to variation in density (ensemble density feedback; sensu Herrando-Pérez et al. 2012) is achieved through demographic rates such as survival and recruitment (i.e., component density feedbacks). However, compensatory survival has not been generally supported by evidence (e.g., Cooley et al. 2009 and Servanty et al. 2011, but revealed in Bartmann et al. 1992; see Lebreton 2005 for theoretical perspectives). Likewise, enhanced recruitment has been demonstrated under longterm selective pressures (e.g., Servanty et al. 2011) but rarely for annual compensation (example in Byrom 2002). Moreover, the strength of component density feedbacks is only weakly related to the strength of the ensemble density feedbacks measured in bird and mammal populations (Herrando-Pérez et al. 2012). This mismatch might partially originate from the failure to account for the open nature of wild populations that practitioners often face.

Indeed, there is growing empirical evidence on the crucial role of immigration from surrounding areas in compensating for local culling (hereafter compensatory immigration, Beasley et al. 2013), especially in mammalian carnivores (Novaro et al. 2005, Loveridge et al. 2007, Cooley et al. 2009, Andreasen et al. 2012, Reynolds et al. 2013). This spatial process may impair management actions because the geographic scale may exceed that of management areas (Bryce et al. 2011; e.g., fox dispersal distances in Illinois: $45 \mathrm{~km}$ in average; range: $1-478 \mathrm{~km}$; Gosselink et al. 2010). In this context, the management solution usually requires extension of the spatial scale of actions. Whereas this might be feasible for range-restricted populations, country-scale management of widely distributed species is typically intractable, both logistically and financially (Saunders et al. 2010). Therefore, there is an urgent need to find a feasible alternative solution to this issue by merging current scientific knowledge with field experiments, in an analogous way to evidence-based conservation (Sutherland et al. 2004).

We developed such an approach in the context of red fox (Vulpes vulpes) culling. For many managers, the aim of fox culling is to maintain reduced densities over the years so as to reduce predation impact on farmed poultry, game species (e.g., lagomorphs and grouse; Baker et al. 2006) and species of conservation concern (ground-nesting birds, e.g., lapwing and plover; Fletcher et al. 2010). The effectiveness of culling in reducing fox densities at a regional scale has been much debated over the last decades (Hewson 1986, Heydon and Reynolds 2000, Aebischer et al. 2003, Baker and Harris 2005). In Australia, where the red fox is an invasive species, long-term and large-scale poisoning programs did not necessarily benefit endemic endangered species (Saunders et al. 2010, Walsh et al. 2012). As for many mammalian carnivores, compensatory immigration is thought to underpin the resistance of fox populations to control (Hewson 1986, Harding et al. 2001, Rushton et al. 2006). To date, evidence-based fox management is still lacking, precluding the spread of relevant guidelines.
To bridge this gap, we designed, together with local practitioners, a field experiment to measure at a regional scale $\left(100-1,000 \mathrm{~km}^{2}\right)$ the effect on fox densities of manipulated culling effort in 5 sites over 5-6 years. We calculated realized culling rates based on an exhaustive collection of carcasses from hunters and trappers. We estimated fox densities from spotlight counts using distance sampling methods allowing valid among-site comparisons by correcting for imperfect detectability (Ruette et al. 2003). We derived population growth rates from these estimations. Our objectives were threefold. First, we wanted to quantify the required culling rate for maintaining stable fox densities at the observed average density (1 fox $\left./ \mathrm{km}^{2}\right)$. Second, we measured sitespecific culling impacts to investigate whether the population response to culling varied according to the demographic context (i.e., how close the population density was from the carrying capacity). Finally, we aimed at identifying a culling strategy that minimizes the compensatory response of foxes for the same effectiveness, and therefore reduces the number of animals killed and the effort of local practitioners, in a context of limited financial and human resources. To achieve this, we compared the impact of culling between distinct periods along the species life cycle, specifically contrasting breeding versus dispersal periods. Indeed, if immigration is the main compensatory process in red fox dynamics, we expected post-dispersal culling to be less compensated for than culling during the breeding period.

\section{STUDY AREA}

The French Game and Wildlife Agency (ONCFS) and the associations of hunters and trappers manipulated year-round fox culling in 5 management units $\left(246 \pm 53 \mathrm{~km}^{2}\right.$; Fig. S1 available online at www.onlinelibrary.wiley.com) located in 2 French regions at the same latitude: Brittany (sites A, B, and $\mathrm{C} ; \geq 10 \mathrm{~km}$ apart) and Champagne (sites D and E separated by the Seine River). The study took place from 2002 to 2012, but was not synchronous across all 5 sites. Hunting (fox drives with or without dogs, ultimately killed by shooting) occurred between October and February, and trapping occurred between December and April. Culling at the den occurred in April. Night shooting occurred only in sites D-E between December and May.

\section{METHODS}

\section{Culling Survey}

The experiment consisted of asking local hunters and trappers to increase their culling effort compared to basal level, without any bounty. The increased effort was, however, not directly quantified in terms of culling activity. In Brittany (sites A, B, and C), hunters and trappers culled an average of $1.95 \pm 0.74$ foxes $/ \mathrm{km}^{2} / \mathrm{yr}$, from February 2003 (Feb 2002 for site A) to January 2007. In Champagne (sites D and E), the culling strategy followed a control impact design between 2006 and 2012. Hunters and trappers increased their effort in site D from February 2009 to January 2012, and in site E from February 2006 to January 2009. Basal hunting effort was applied between 2006 and 2009 in D and between 2009 
and 2012 in E. The basal and intense culling effort resulted in $0.46 \pm 0.08$ and $1.30 \pm 0.23$ foxes $/ \mathrm{km}^{2} / \mathrm{yr}$, respectively. Across all sites and years of study, the annual culling bag averaged $1.46 \pm 0.85$ foxes $/ \mathrm{km}^{2} / \mathrm{yr}$ (range: $0.34-4.1$; Table S1).

All cub and adult carcasses were collected from hunters and trappers by ONCFS, providing a precise annual culling bag. The culling method and locality were also recorded (Table S2). Because of the advanced deterioration of some carcasses, only $65 \%$ of carcasses were analyzed (aged from tooth cementum, count of placental scars) in Brittany and $90 \%$ in Champagne. The date of death was recorded for the analyzed carcasses only. A management year started on 1 February when we performed spotlight counts. We delineated periods (Fig. 1 and Table S2) as follows: the gestation period $\left(K_{\mathrm{G}}\right)$ was when only adult residents were present (Feb-Mar), the breeding period $\left(K_{\mathrm{B}}\right)$ started at cub birth and lasted as long as cubs stayed in the den (Apr-Jun; Ruette and Albaret 2011), and the dispersal period $\left(K_{\mathrm{D}}\right)$ lasted from late spring to mid-winter when both adults and juveniles might have dispersed and found territories (JulJan). Thus, bags included adult and cubs for $K_{\mathrm{B}}$ and $K_{\mathrm{D}}$. The known number of non-analyzed carcasses was annually distributed among $K_{\mathrm{G}}, K_{\mathrm{B}}$, and $K_{\mathrm{D}}$, according to the temporal distribution of analyzed carcasses among the different methods used.

The age at death was determined from the carcasses based on the number of annual growth lines visible in the tooth cementum (Ruette and Albaret 2011; Matson's laboratories,

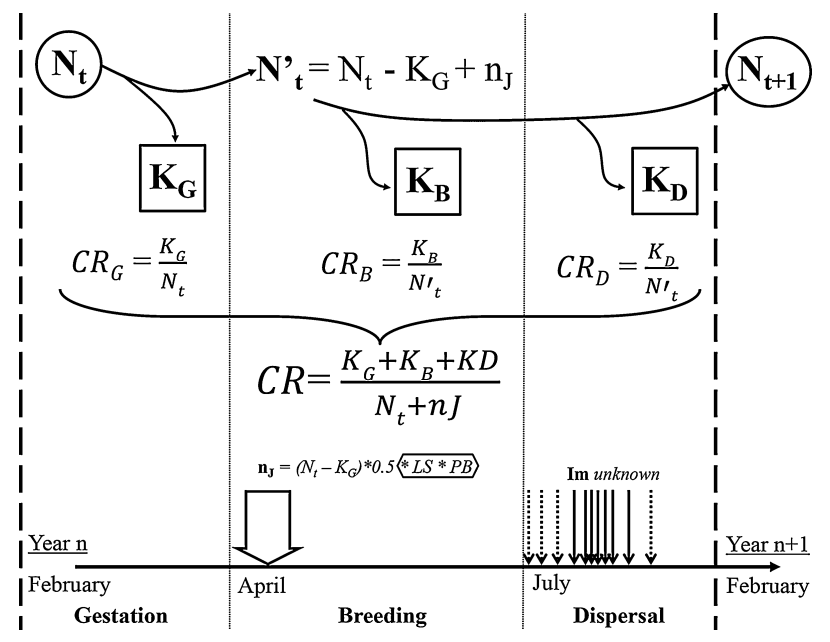

Figure 1. Culling rate projected on the red fox life cycle for foxes in northern France. A year is divided into 3 life periods: gestation ( ${ }_{\mathrm{G}}$; FebMar), breeding ( $\mathrm{B}$; Apr-Jun), and dispersal ( $\mathrm{D}$; Jul-Jan). Information sources are spotlight counts (circle; adult abundance estimation $N_{t}$ in Feb), uterus examination (hexagon; proportion of breeding females $P B$ and litter size $L S$ ), and culling bags of the 3 periods: $K_{\mathrm{G}}, K_{\mathrm{B}}$, and $K_{\mathrm{D}}$ (squares). This information enabled the calculation of an annual culling rate $C R$ and its distribution among the 3 periods $\left(C R_{G}, C R_{\mathrm{B}}\right.$, and $\left.C R_{\mathrm{D}}\right)$. Each culling rate corresponds to the ratio of the number of killed foxes by the potential number of foxes that could have been killed during the same period. Arrows indicate the birth period given $n_{J}$, estimated from uterus examination and the period of immigration (Im), characterized according to the literature, by a peak around September (solid arrows) and possible arrivals from early July to late winter (dotted arrows).
Milltown, MT, USA). We assigned foxes to age classes based on their recruitment into the adult population on 1 February of the year following birth (i.e., at the age of 10 months when foxes were deemed sexually mature and undifferentiated from older animals). From 10 months, foxes were classified as adults, whereas foxes less than 10 months old were classified as cubs. We collected undamaged uteri from 899 vixens. We estimated litter size for 755 reproductive vixens from the count of embryos and placental scars (Ruette and Albaret 2011).

\section{Density Estimation}

We estimated fox densities using spotlight counts during the first 2 weeks of February, when only adults were present (Ruette et al. 2003; Supplemental Material 3). We performed line-transect surveys each year in Brittany sites (number of transects: $A=49, B=38, C=38$ ), whereas we used point-transect surveys in Champagne sites $(D=90$, $E=103)$. The change of method occurred after a modification of road safety legislation, but both methods gave similar results when conducted simultaneously in the same site (Ruette et al. 2003). We accounted for imperfect detectability using multiple-covariate distance sampling (Buckland et al. 1993, Marques et al. 2007). We completed all analyses in DISTANCE 6.0 (Thomas et al. 2009, http://www.ruwpa. st-and.ac.uk/distance, accessed 25 Oct 2012). We derived confidence intervals from a bootstrap method $(n=999)$. This method gave $N_{t}$, the initial population size every year (Fig.1).

\section{Population Modeling}

For each site, we estimated annual and age-specific reproductive performance as average litter size $(L S)$ and proportion of breeding females ( $P B$; Table S2). We calculated the annual number of cubs $n_{J}$ born in April (Fig. 1) retrospectively given the estimated age-specific reproductive parameters $(L S$ and $P B)$, the female culling bag in April $\left(N_{\mathrm{t}} \times 0.5-K_{G} \times 0.5\right.$, where 0.5 is the proportion of females in the adult population), and $C_{i}$, the proportion of adult females of age $i$ in this bag:

$$
n_{J}=\sum_{i=1}^{10} \mathrm{LS}_{i} \times \mathrm{PB}_{i} \times\left(N_{\mathrm{t}}-K_{\mathrm{G}}\right) \times 0.5 \times C_{i}
$$

We defined a culling rate as the period-specific cull divided by the estimated number of foxes available at the start of each period (culling potential hereafter; Fig. 1). To estimate the culling rate during gestation $\left(C R_{G}\right)$, the culling potential was the adult population size estimated in February, $N_{t}$. We assumed that in April, $N_{\mathrm{t}}-K_{\mathrm{G}}$ remaining adults gave birth to $n_{J}$ cubs. The culling potential $N_{t}^{\prime}$ was thus the remaining adults $\left(N_{\mathrm{t}}-K_{\mathrm{G}}+n_{J}\right)$. $\mathrm{N}_{\mathrm{t}}^{\prime}$ allowed us to estimate culling rates during both the breeding and dispersal periods $\left(C R_{\mathrm{B}}\right.$ and $C R_{\mathrm{D}}$, respectively). We could not directly calculate $C R_{\mathrm{D}}$ because, during this period, an unknown number of immigrant foxes enters the focal population, therefore preventing a proper estimate of foxes available for culling. To circumvent this issue, we chose to calculate $C R_{\mathrm{D}}$ relative to $N_{t}^{\prime}$ (i.e., not accounting for $K_{\mathrm{B}}$ ). By so doing, $C R_{\mathrm{D}}$ 
remained interpretable as a proportion of the initial population that have been killed and remained meaningful for setting quotas. Finally, the annual culling potential referred to $N_{t}+n_{J}$, so that we estimated an annual culling rate $(C R)$.

We aimed at explaining the response of annual population growth rate $\left(\lambda_{t}=N_{t+1} / N_{t}\right)$ to variation in culling rates. Additional explanatory variables included density (D) measured in the different sites to account for density feedback. Given the maximum population growth rate $\left(\lambda_{\max }\right)$ of the species and the site-specific carrying capacity $(\kappa)$, we assumed that any fox populations followed a logistic growth of the form (Skalski et al. 2005):

$$
N_{\mathrm{t}+1}=N_{\mathrm{t}}+N_{\mathrm{t}}\left(\lambda_{\max }-1\right)\left(1-N_{\mathrm{t}} / \kappa\right)
$$

Then, investigating ensemble density feedback requires transforming (2) in:

$$
\lambda_{\mathrm{t}}=\beta_{0}+\beta_{1} D_{\mathrm{t}} \text { with } \beta_{0}=\lambda_{\max } \text { and } \beta_{1}=\left(1-\lambda_{\max }\right) / \kappa
$$

We used linear mixed models (LMM) because our limited data set $(n=28$ site $\times$ year $)$ precluded the investigation of non-linear models, and because we were interested in making predictions for an average population and not for each specific site (Zuur et al. 2009). We built 2 sets of models: 1 considering the impact of annual culling and another investigating the influence of a period-specific management. For both sets of models, we followed the model selection procedure recommended by Zuur et al. (2009).

Our starting model contained culling rate and density in interaction as fixed effects. Variation in natural mortality or reproduction could not specifically be accounted for in the model, because longitudinal data on individuals was lacking. The model equation concerning annual culling impact was:

$$
\lambda_{\mathrm{t}}=\beta_{0}+\beta_{1} D_{\mathrm{t}}+\beta_{2} C R_{\mathrm{t}}+\beta_{3} D_{\mathrm{t}} C R_{\mathrm{t}} .
$$

In a first step, we looked for potential autocorrelation within the measurement time-series at each site and we found that an autoregressive structure of first order improved the model ( $\pi=-0.75$; Likelihood ratio: $6.46 ; P=0.011)$. In a second step, we tested a variety of random effects that take site specificity into account (Table S4) keeping the initial fixed effect and autoregressive structures. We expected site specificity to act on the strength of density feedback $\left(\beta_{1}\right)$ because of difference in $\kappa$, and on the interaction between density and culling rate $\left(\beta_{3}\right)$, if the magnitude of compensation changed with $\kappa$ (Péron 2013). We also expected $\lambda_{\max }$ to be constant among sites. We tested first the relevance of a random effect of the site on the slope $\beta_{1}$ of the density feedback and/or on the intercept $\beta_{0}$. Then, we added a random effect of the site on the slope $\beta_{3}$ of culling impact only if a random effect on density feedback was selected.

We selected models (Table S4) according to Akaike's Information Criterion corrected for small sample size (AIC ; $_{i}$ Burnham and Anderson 2002). If a random effect on the strength of density feedback was selected, we were able to derive site-specific $\kappa$ from $\beta_{1}$, given an estimation of $\lambda_{\max }$ using $\beta_{0}$ (Chamaillé-Jammes et al. 2008). For each site, $\kappa$ corresponded to the predicted density when $\lambda=1$ and the
$D / \kappa$ ratio measured how close average observed density was below $\kappa$. These estimations assumed that site-specific $\kappa$ was constant over the years. Concerning the second set of models with period-specific culling rates $\left(C R_{i}\right)$, we encountered a convergence issue that prevented us from using the full random structure. So, we limited the complexity of the model by adding only a random effect on the density feedback $\beta_{1}$. We investigated the influence of the $D / \kappa$ ratio on culling impact only by the fixed interaction between $C R_{i}$ and $D$, ignoring site specificity.

We built a set of candidate models containing $C R$ and $D$ with and without their interactions. We selected the best fixed effects based on $\mathrm{AIC}_{c}$ and assessed model fit on a visual inspection of residuals. We predicted the strength of the density feedback along the range of observed densities given zero culling. Then, we predicted culling impact along the range of observed culling rates for 2 levels of density: the observed average $\left(1 \mathrm{fox} / \mathrm{km}^{2}\right)$ and a lower level $\left(0.5\right.$ fox $\left./ \mathrm{km}^{2}\right)$ to represent a situation of lower $D / \kappa$ ratio. Because we estimated densities with uncertainty, we performed a bootstrap procedure with a random sampling of densities $\left(n_{\mathrm{b}}=1,000\right)$ in their estimated range before culling rate estimation, model selection, and predictions (Supplemental Material 5). This bootstrap allowed us to propagate the uncertainty over our predictions. Lastly, when looking at $C R_{i}$, we identified an issue of collinearity between $C R_{\mathrm{G}}$ and $C R_{\mathrm{D}}$ (variance inflation factors of $C R_{\mathrm{G}}$ and $C R_{\mathrm{D}}>2.5$; Zuur et al. 2009). As a consequence, we avoided interpretation based on a single best model and we used a model-averaging procedure after the bootstrap between 3 competing models containing every $C R_{\mathrm{i}}$ as additive fixed effects and each interaction between $C R_{\mathrm{i}}$ and $D$, compared to the model without interactions. We ran all analyses with R.2.15.1 (R Development Core Team 2012, www.r-project.org, accessed 10 Dec 2012), using packages nlme (Pinheiro et al. 2013; http://cran.r-project.org/web/packages/nlme, accessed 25 Feb 2013) and AICcmodavg (Mazerolle 2012; http://cran. r-project.org/web/packages/AICcmodavg, accessed 15 Dec 2012; see Supplemental Material 6 for R codes).

\section{RESULTS}

\section{Density Variations Under Contrasting Culling Effort}

Annual culling rates $(C R)$ varied across sites from $30 \%$ to $176 \%$. In sites A, B, and C, CR fluctuated around $60 \%$ of the estimated population size (Fig. 2 and Table S2). The observed decrease in $C R$ and increased density after February 2005 for sites A and B highlight the difficulty for managers to sustain an intense effort over more than 2-3 years. In sites $\mathrm{D}$ and $\mathrm{E}$, the experimental design met the target, with $C R$ during periods of low culling intensity being on average $40 \%$, whereas periods of intense effort achieved an average $C R$ of $140 \%$.

Overall, density estimates varied from 0.3 to 2.5 foxes $/ \mathrm{km}^{2}$ across sites (Fig. 2 and Table S2): around 1 in A and C, 2.25 in $\mathrm{B}$, and 0.5 in $\mathrm{D}$ and $\mathrm{E}$. In sites $\mathrm{A}$ and $\mathrm{B}$, fox densities increased by $56 \%$ and $34 \%$ over 5 years, respectively, despite an applied $C R$ of $60 \%$. The same pattern was observed during 

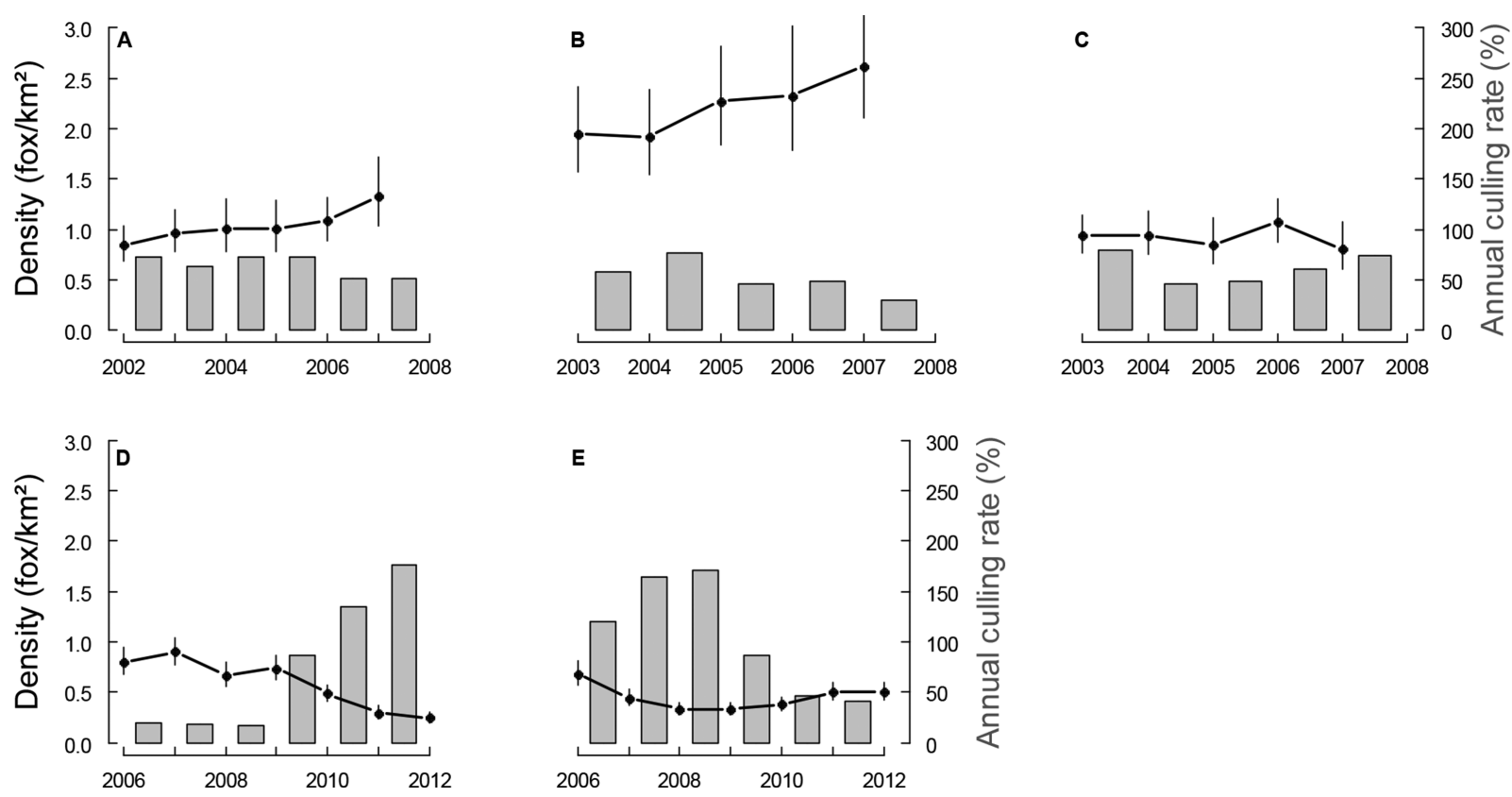

Figure 2. Simultaneous variations of annual fox density and culling rate in sites A to E in northern France. Densities in fox $/ \mathrm{km}^{2}$ are presented with $95 \%$ confidence intervals (black dots with error bars) derived from a bootstrap procedure. Associated annual culling rates (CR) correspond to the proportion of available individuals in the area that have been killed (grey bars).

the period of low culling intensity at site $\mathrm{E}(47 \%$ increase between Feb 2009 and 2012). In contrast, densities did not increase in sites $\mathrm{C}$ and $\mathrm{D}$ during periods with similarly low culling intensity. Finally, intense culling in sites D and E induced a decrease in density of $51 \%$ and $59 \%$, respectively.

\section{Influence of Compensatory Density Feedback on Culling Impact}

Red fox population growth experienced ensemble compensatory density feedback (Table 1, Fig. $3 \mathrm{~A} ; \Delta \mathrm{AIC}_{c}=7.67$ when compared to the model without density feedback). The site-averaged estimates corresponded to a population with $D=1.02 \pm 0.63 \mathrm{fox} / \mathrm{km}^{2}$ and $\kappa=1.5 \pm 0.6$. The strength of density feedback depended on the site-specific carrying capacity $(\kappa)$. Observed densities never exceeded estimated $\kappa$. The closer the density was to $\kappa$, the stronger the compensatory density feedback (Table 1, Fig. 3A). The selected random structure included a site effect affecting density feedback strength (Table S4). Site-specific $\kappa$ was estimated between 0.9 and 8.3 foxes $/ \mathrm{km}^{2}$ (Fig. 3A) and sites differed in their $D / \kappa$ ratio (decreasing from $98 \%$ to $26 \%$ with a sequence of sites D, E, C, A, and B; Table 1). Thus, $\kappa$ was estimated to be higher in the bocage region of Brittany than in the intensive agricultural landscape of Champagne. The maximum population growth rate was estimated at $1.56 \pm 0.07$ across sites (Fig. 3A; Table 1).

Culling impact increased as density approached $\kappa$, i.e., for higher $D / \kappa$ ratio (Fig. $3 \mathrm{~A}$ and $\mathrm{B}$, Table 1 ). For the

Table 1. Model output (fixed and random effects, average and site-specific coefficients) of annual growth rate variations according to fox density (Density), culling rate $(C R)$, and random site-specific carrying capacity $(\kappa)$ for populations of red foxes at 5 sites (A-E) in northern France, 2002-2012. Study sites are sorted in increasing values of $\kappa$.

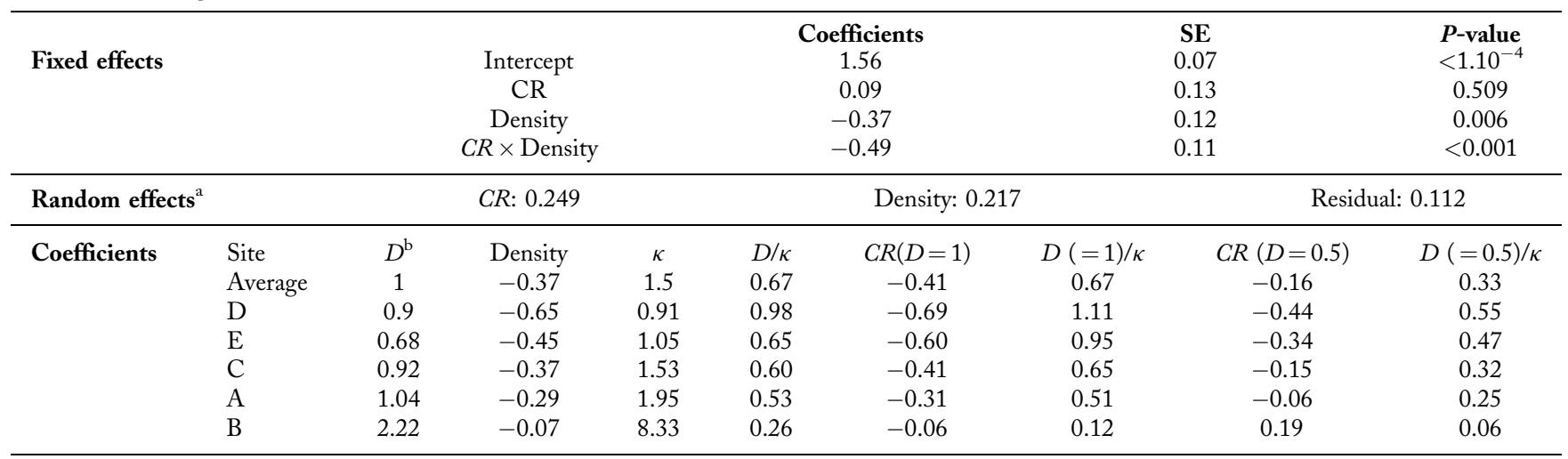

${ }^{\text {a }}$ Standard deviation associated with the random effect of site on the slope of culling rate $(C R)$ and density feedback (Density).

b Average density (foxes $/ \mathrm{km}^{2}$ ) of each site during the study period. 

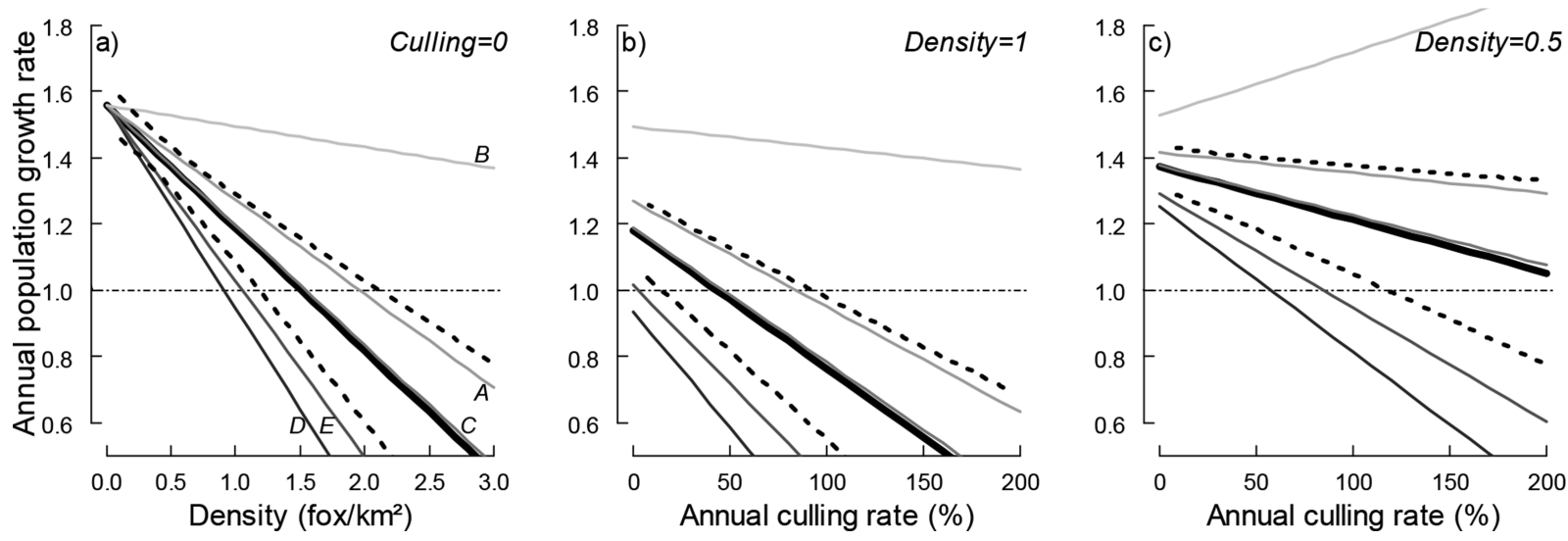

Figure 3. Model predictions of annual growth rate according to fox density and annual culling rate in northern France, 2002-2012. The thicker line corresponds to the site-averaged estimates $(\kappa \sim 1.5)$ with associated standard errors (dotted lines). Thinner lines correspond to the site-specific random slopes of our 5 study sites (A-E), as indicated in the left graph. The darker the shade of grey, the smaller $\kappa$, the carrying capacity of the site and the closer the site-average density to $\kappa$. Predictions are drawn a) according to density given a null annual culling rate; the common intercept identifies the maximum population growth rate $\lambda_{\max }$ of the species and the intersections of slopes with $\lambda=1$ correspond to $\kappa$; b) according to annual culling rate given densities of 1 (i.e., the site-average), or $\mathrm{c}$ ) given densities of 0.5 (a situation at a lower density/ $\kappa$ ratio).

site-averaged situation (Fig. 3B), we predicted a significant impact of annual culling with $C R$ of $45 \%$ (visual range of confidence 20-80\%) to maintain the population growth at 1. However, below an approximate $D / \kappa$ ratio of $25-32 \%$, we predicted a decrease of culling impact, which was then unable to prevent population growth (Fig. 3A and B; Table 1). This variation of culling impact according to the $D / \kappa$ ratio was revealed by a significant interaction between culling rate and density (Table $1 ; \Delta \mathrm{AIC}_{c}=2.76$ when compared to the model without interaction). Site-specificity was highlighted by a random effect of site affecting culling impact (Table S4). The identification of density feedback and average culling impact was robust to bootstrapping (Supplemental Material 5).

\section{Period-Specific Culling Impact and Compensatory Immigration}

If culling effort had been restricted to a specific period along the red fox life cycle, only culling during dispersal would have significantly affected population growth (Fig. 4; Table 2). In contrast, culling during gestation or breeding would have had no impact on density in the following February, i.e., it would have been compensated for (Fig. 4A and B). Moreover, in the site-averaged situation, concentrating culling during dispersal would have required only $25 \%$ of animals killed to maintain stability (Fig. 4C) instead of $45 \%$ for culling all year round (Fig. 3B).

Finally, interpreting the influence of density feedback on period-specific culling impact was more difficult with our data (Table 2). The model without an interaction between density and period-specific culling had greater AIC weight and the coefficients of the models with an interaction had large confidence intervals. This indicated that none of these interactions were significant (Table 2).

\section{DISCUSSION}

The analysis of our experiment suggests that a strong compensation by immigration negated the effect of red fox culling conducted in farming landscapes of France. We
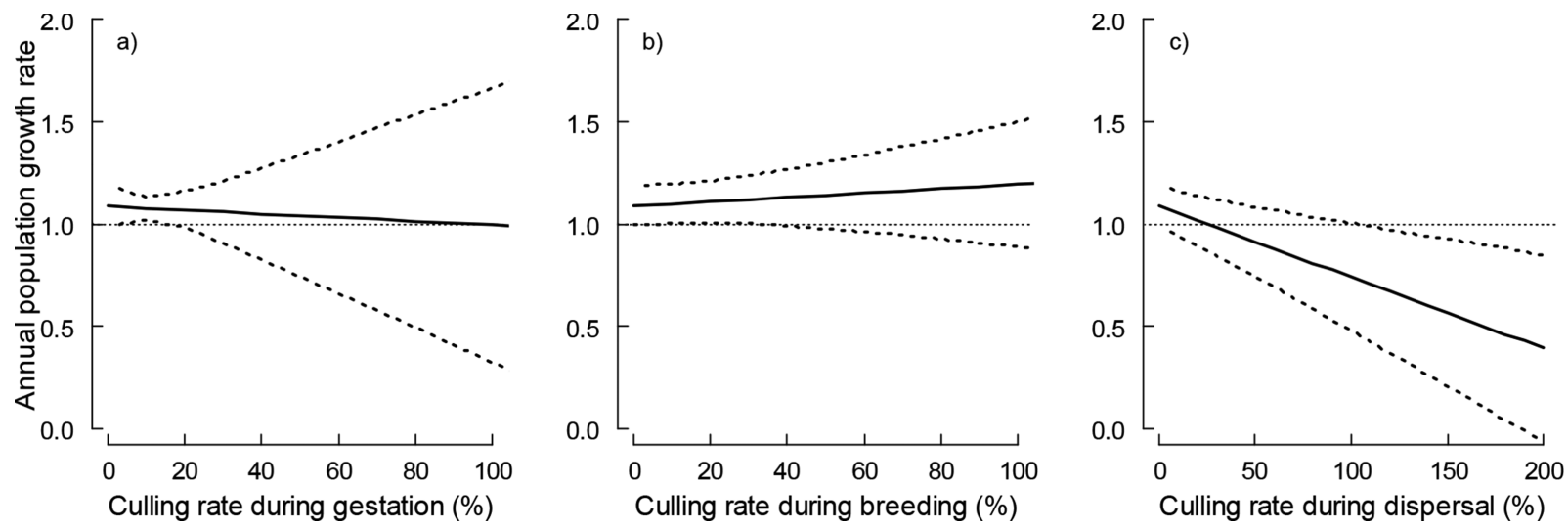

Figure 4. Model-averaged predictions after bootstrap of annual growth rate according to period-specific culling rates $(C R)$ of red foxes in northern France, 2002-2012: a) $C R_{\mathrm{G}}$ during gestation, b) $C R_{\mathrm{B}}$ during breeding, and c) $C R_{\mathrm{D}}$ during dispersal. The solid line corresponds to the site-average situation $(\kappa \sim 1.5)$, dashed lines are associated standard deviation, and predictions are given holding all other culling rates at 0 and with a density of 1 (i.e., the site-average; dotted line). 
Table 2. Model output after bootstrap of annual growth rate variations according to density (Density) and culling rate of red foxes in northern France, 20022012, during gestation $\left(C R_{\mathrm{G}}\right.$; Feb-Mar), breeding $\left(C R_{\mathrm{B}}\right.$; Apr-Jun), and dispersal ( $C R_{\mathrm{D}}$; Jul-Jan). For each model, we provide Akaike's Information Criterion weights $(\mathrm{AICw})$ and coefficient estimates $( \pm \mathrm{SD})$. We also provide model-averaged predictions of period-specific culling impact for 2 levels of density.

\begin{tabular}{|c|c|c|c|c|c|c|}
\hline Model & $\mathrm{AICw}$ & Density & $C R_{\mathrm{G}}$ & $C R_{\mathrm{B}}$ & $C R_{\mathrm{D}}$ & Interaction \\
\hline$C R_{\mathrm{G}} \times$ Density $+C R_{\mathrm{B}}+C R_{\mathrm{D}}$ & 0.11 & $-0.31 \pm 0.35$ & $0.15 \pm 1.04$ & $0.11 \pm 0.29$ & $-0.37 \pm 0.21^{\mathrm{a}}$ & $-0.36 \pm 0.86$ \\
\hline$C R_{\mathrm{G}}+C R_{\mathrm{B}} \times$ Density $+C R_{\mathrm{D}}$ & 0.13 & $-0.31 \pm 0.32$ & $-0.16 \pm 0.76$ & $0.27 \pm 0.44$ & $-0.34 \pm 0.20^{\mathrm{a}}$ & $-0.31 \pm 0.70$ \\
\hline$C R_{\mathrm{G}}+C R_{\mathrm{B}}+C R_{\mathrm{D}} \times$ Density & 0.16 & $-0.38 \pm 0.31$ & $0.07 \pm 0.78$ & $0.17 \pm 0.28$ & $-0.48 \pm 0.29^{\mathrm{a}}$ & $0.14 \pm 0.25$ \\
\hline$C R_{\mathrm{G}}+C R_{\mathrm{B}}+C R_{\mathrm{D}}$ & 0.60 & $-0.36 \pm 0.32$ & $-0.12 \pm 0.74$ & $0.15 \pm 0.26$ & $-0.35 \pm 0.20^{\mathrm{a}}$ & \\
\hline \multicolumn{3}{|c|}{ Model-averaged predictions $($ Density $=1)$} & -0.10 & 0.11 & -0.35 & \\
\hline \multicolumn{3}{|c|}{ Model-averaged predictions $($ Density $=0.5)$} & -0.03 & 0.16 & -0.38 & \\
\hline
\end{tabular}

${ }^{a}$ Significant effect with a standard deviation lower that the associated estimate.

quantified the culling impact on red fox population dynamics in different ecological conditions (site-specific carrying capacity $\kappa$ ) and management actions (varying culling effort). We showed that because of strong compensatory density feedback, culling was more likely to reduce late winter density when density was close to $\kappa$ and when applied during the dispersal period.

\section{Compensatory Response of Red Fox Populations by Immigration}

Low culling rates did not succeed in reducing late winter fox density. The recommended intense culling effort was difficult to maintain over 5 years in relatively high-density sites $\left(1-3 \mathrm{fox} / \mathrm{km}^{2}\right)$, and fox densities did not decrease there. In contrast, density halved on low-density sites $\left(<1 \mathrm{fox} / \mathrm{km}^{2}\right)$ as a result of an intense effort; each year more individuals were killed than were estimated to be present before reproduction. In site $\mathrm{E}$, densities partially recovered following the relaxation of culling effort. Overall, our results highlight the ability of red fox populations to compensate for culling.

Compensation in a controlled or harvested population occurs when the remaining individuals show enhanced demographic parameters (Baker et al. 2007). Because our analysis split annual culling into 3 distinct phases of the biological cycle, we were able to infer which parameters (survival, reproduction, or immigration) drove compensation. Culling during the gestation period was compensated for. This compensation could have arisen because of higher survival, reproduction in spring, and/or immigration in autumn. Culling during reproduction had little impact on next-year density, suggesting that recruitment was not involved in compensation. Finally, culling strongly affected population growth when applied intensively during the dispersal period. We hypothesize that the reduction in immigration due to culling during the dispersal phase prevented the recolonization of vacant territories prior to the next breeding season and thus dispersal could no longer compensate for culling. Moreover, the number of foxes killed exceeded the total estimated population size (including adults counted in February and estimated cub numbers), suggesting that immigrants were also killed. Thus, culling might have more impact when applied after most dispersal takes place (late summer and early autumn) up to the beginning of parturition so as to avoid creating vacancies by limiting immigration. This strategy could also take advan- tage of the natural mortality of juveniles in winter (Byrom 2002). Nevertheless, the collinearity between the culling rate of gestation and dispersal periods may imply that culling during gestation could have a higher impact than predicted in our analyses and that compensatory survival may have a non-negligible influence. Gathering new data to quantify immigration (telemetry, capture-recapture data) are required to confirm our results while relaxing our assumptions.

When the objective is to reduce predation on other species (e.g., breeding game birds), an alternative strategy commonly suggested involves targeting lactating females in spring. In our experiment, the culling bag during the breeding period was more female-biased (Table S1), yet it appears to be totally compensated for by next February (Fig. 4B). This suggests that dispersal outweighed the benefit of sex- or agespecific management because the density of adults rearing cubs in spring is very similar to the estimated density in the previous February (very little dispersal takes place at this period). It is likely that shifting culling effort from the breeding period to winter would be equivalent (or perhaps better) in terms of density reduction, and would involve fewer kills. Nonetheless, it remains to be tested by proper field experiments contrasting spring culling (what is usually suggested) and post-dispersal culling.

Our experimental results overall reveal that immigration is likely to be the main process by which compensation operates in the red fox. This has been already hypothesized (Hewson 1986, Heydon and Reynolds 2000, Harding et al. 2001, Rushton et al. 2006, Newsome et al. 2014), but demonstrated only in a different fox species, Pseudalopex culpaeus (Novaro et al. 2005). Such demographic response can be explained by the high proportion of juveniles ( $73 \%$ for males and $32 \%$ for females) and adults (around 33\% for both sex; Trewhella et al. 1988) having the potential to disperse over long distances (e.g., in Illinois, USA: $45 \mathrm{~km}$ in average; range: 1$478 \mathrm{~km}$; Gosselink et al. 2010). Because this range exceeds the gap between our study sites within a region (approx. $10 \mathrm{~km}$ apart in Brittany, the width of the Seine river in Champagne), abutting sites cannot be considered as fully independent demographically. However, much of the area surrounding our study sites was non-manipulated and therefore represented a substantial source of immigrants (Fig. S1). Further work is needed to understand potential mechanisms underlying compensatory immigration in terms of dispersal behavior. Our results suggest that the probability of a fox settling in a particular site is likely to be 
density-dependent, with foxes transiting through a heavily culled site (therefore with low density) having a higher probability to settle there.

\section{Field-Derived Estimates of Culling Impact on Red Fox Population Dynamics}

Besides the characterization of the compensatory response, we quantified the culling impact on population growth to predict the culling rate needed for stabilizing density around $1 \mathrm{fox} / \mathrm{km}^{2}$ (i.e., the average density in this study). We predicted that around $45 \%$ of the estimated numbers of individuals based on February counts had to be killed, although estimates strongly differed among sites (from $0 \%$ in site $\mathrm{D}$ to $650 \%$ in site A; Fig. 3B). How reliable is this culling rate and how relevant is it for management actions?

The accuracy of a culling rate may suffer from uncertainty in both the culling bag and population density estimates. Concerned by the reliability of data collected by a network of volunteers (Macdonald and Johnson 1996), we systematically and directly collected carcasses of hunted foxes so as to obtain a precise annual culling bag. We estimated densities using distance sampling methods to account for imperfect detection of animals (Buckland et al. 1993). Yet, our estimates may be slightly underestimated because of a lower detection rate at the shortest distances, possibly stemming from individuals fleeing the approaching vehicle hiding in surrounding hedges, woods, or topographic depression. These foxes, not accounted in the curved detection function (see Supplemental Material 3), could have induced a slight violation of the assumption of complete detection on the transect and led to over-estimated culling rates (max. 160$180 \%)$. There was, however, no reason for this bias to vary over time, and population growth rates were therefore properly estimated. Furthermore, derived guidelines remain practically valid as long as densities are estimated with the same protocol each year. For the above reasons, we are confident that our estimates of culling rate reached a high level of accuracy.

Notably, our predictions of the required proportion of kill for the site-averaged model fall in the lower range of those from modeling studies: 60\% of individuals (Macdonald and Johnson 1996), $50 \%$ of adults and $25 \%$ of juveniles (Harding et al. 2001), 65\% of individuals (Hone 1999), and $60-80 \%$ of individuals (Rushton et al. 2006). However, the uncertainty of our estimates remained large (visual range 20-80\%; Fig. 3). Besides sampling variance due to the limited number of replicates (inherent to the spatial scale of this study), a substantial amount of variance arose from the ecological context of each site (e.g., carrying capacity, past culling regimes).

\section{Site-Specific Culling Impact According to Variation in Carrying Capacity}

Fox populations experienced compensatory ensemble density feedback, even in the absence of culling. Their intrinsic growth was limited by the carrying capacity of the habitat. Except for extreme variations of food availability in the arctic environment or suburban areas (Bino et al. 2010), this generalist predator is known to be weakly influenced by annual variations in food supply (e.g., vole cycles) over its temperate distribution (Baker et al. 2006). Thus, we assumed that $\kappa$ did not vary between years but among sites (O'Mahony et al. 1999). We estimated greater $\kappa$ in the bocage region of Brittany than in the intensive agricultural landscape of Champagne, probably because of the lower food abundance and diversity associated with intensive crops. In particular, the availability of human wastes in a town of 20,000 inhabitants in site B might explain a high estimated value of $\kappa$ (Bino et al. 2010).

Our analysis revealed that this variation of $\kappa$ among sites influenced the compensatory response of fox populations through immigration. We found that the magnitude of culling compensation increased the further the density was from $\kappa$. Intrinsically (i.e., without culling), the compensatory density feedback was stronger when $D$ was close to $\kappa$. In this situation, there may be a large number of resident nonbreeding individuals that will immediately fill territories vacated by natural death or culling. Assuming that nonbreeders have lower survival (e.g., Harding et al. 2001), compensatory survival is therefore expected to be stronger in this situation and immigration is limited by the precedence of resident animals. In contrast, we found that compensatory immigration after culling increased significantly when $D$ was far below $\kappa$. In this case, individuals that fill vacant territories are expected to be mostly immigrants, as there are virtually no local non-breeders. In extreme cases, immigration may drive post-culling densities to exceed pre-culling densities (Fig. 3C). Overall, because the compensation of culling effects was the weakest in the situation where compensatory survival seemed the strongest, we hypothesized that variation in non-culling mortality should be negligible relative to the importance of immigration.

The practical consequence of these variations in the magnitude of compensation was that successful reduction of red fox densities could have been obtained above $25-32 \%$ of the site-specific carrying capacity $(\kappa)$. Successful management appeared to be very difficult to achieve below this threshold. Moreover, long-term fox control requires an intense and continuous effort. At high density ( $>1$ fox $/ \mathrm{km}^{2}$, independent of proximity to $\kappa$ ), the number of foxes to be killed may exceed our local management capacity. Sitespecificity (current density and $\kappa$ levels) is thus a key component of fox management that should be accounted for by practitioners (Heydon and Reynolds 2000). If the estimation of the carrying capacity remains a practical issue, available data should allow us to broadly characterize the density level according to habitat types (e.g., 94 sites monitored by the kilometric abundance index in France, $\mathrm{S}$. Ruette and M. Albaret, Office National de la Chasse et de la Faune Sauvage, unpublished data). Switching from indices (e.g., feces count, kilometric abundance) to density estimation that accounts for detectability is a first step for comparing population trends among sites. Although the strategy of predator control we previously proposed came from fox culling taking place in 5 different sites from 2 distinct farming landscapes in France and was based on a particular combination of removal methods, we believe our 
results might provide a suitable framework in which further culling protocols could be tested in other types of landscapes, using different fox culling practices, as well as in other controlled mammalian predators. We expected that such multi-site replication would help in generalizing the scope of the guidelines we proposed.

\section{MANAGEMENT APPLICATIONS}

Our study provides support for immigration as the main compensatory demographic response of red fox to control, as in several territorial carnivores (Loveridge et al. 2007, Cooley et al. 2009, Andreasen et al. 2012, Beasley et al. 2013, Reynolds et al. 2013). On small spatial scales (approx. $10 \mathrm{~km}^{2}$ ), removal would quickly be cancelled out through immigration and would therefore have to be repeated annually with the same effort, if we are to control fox populations trends on the long-term. Extending the spatial scale of actions is usually proposed as a management solution to this issue (Saunders et al. 2010). However, country-scale management of widely distributed species, like the red fox, is typically intractable (but see Bryce et al. 2011, Reynolds et al. 2013). In particular, our study shows that fox culling at a regional scale (i.e., $100-1,000 \mathrm{~km}^{2}$ ) underwent similar compensation. Our results do show, however, that culling can be made much more efficient if done in the proper season. A strategy concentrating culling effort in winter might be more effective than year-round culling in reducing year-to-year adult fox densities and would reduce the culling rate required by half (approx. 50\% of the observed cull was taken outside the advocated period). To build strong evidence-based management, we call for more experimental approaches like ours, e.g., testing the relative effectiveness of year-round culling (what is usually done), post-dispersal culling only (what we propose), and no culling at all. Ultimately, these control experiments should also investigate the effects of fox culling on game population dynamics as well as species of conservation concern, which represent the main objective of practitioners involved in predator control. Nevertheless, the control guideline proposed here is tractable and could be implemented in the field for a wide range of species showing compensatory immigration, especially carnivorous mammals. This illustrates how experimental protocols, designed by practitioners and ecologists together, can improve population control by reducing local practitioners' effort in a context of limited financial and human resources but also contribute to reducing the ethical concern of killing a large number of animals.

\section{ACKNOWLEDGMENTS}

We are grateful to the regional and local Hunters' Associations, especially Y. Desmidt, J.-L. Pilard, P. Hecht, C. Mercuzot, J. Desbrosse, and C. Urbaniak for sustaining the program. We warmly thank N. Haigron, C. Mangeard, and T. Mendoza for efficient support in the fieldwork, our colleagues working on hares, especially Y. Bray and J. Letty and all local people in charge of hunting, and hunters and trappers who helped in counting and collecting foxes. $\mathrm{H}$. Santin-Janin, X. Lambin, and M. Valeix improved first draft of this manuscript and C. Carter kindly edited the English. We also thank 2 anonymous reviewers for their thorough comments. This study was partially funded by the Regional Hunters' Association of Champagne-Ardenne, and the Hunters'Associations of Aube and Ille-et-Vilaine.

\section{LITERATURE CITED}

Aebischer, N. J., S. E. Baker, P. J. Johnson, D. W. Macdonald, and J. C. Reynolds. 2003. Ecology: hunting and fox numbers in the United Kingdom. Nature 423:400.

Andreasen, A. M., K. M. Stewart, W. S. Longland, J. P. Beckmann, and M. L. Forister. 2012. Identification of source-sink dynamics in mountain lions of the Great Basin. Molecular Ecology 21:5689-5701.

Baker, P. J., and S. Harris. 2005. Does culling reduce fox (Vulpes vulpes) density in commercial forests in Wales, UK? European Journal of Wildlife Research 52:99-108.

Baker, P. J., S. Harris, and P. White. 2006. After the hunt: the future for foxes in Britain. International Fund for Animal Welfare, Bristol, United Kingdom.

Baker, S. E., G. Singleton, and R. Smith. 2007. The nature of the beast: using biological processes in vertebrate pest management. Pages 173-185 in D. MacDonald, and K. Service, editors, Key topics in conservation biology. Blackwell Publishing, Hoboken, New Jersey, USA.

Bartmann, R., G. White, and L. Carpenter. 1992. Compensatory mortality in a Colorado mule deer population. Wildlife Monographs 121:3-39.

Beasley, J. C., Z. H. Olson, W. S. Beatty, G. Dharmarajan, and O. E. Rhodes. 2013. Effects of culling on mesopredator population dynamics. PloS ONE 8:1-9.

Bino, G., A. Dolev, D. Yosha, A. Guter, R. King, D. Saltz, and S. Kark. 2010. Abrupt spatial and numerical responses of overabundant foxes to a reduction in anthropogenic resources. Journal of Applied Ecology 47:1262-1271.

Bryce, R., M. K. Oliver, L. Davies, H. Gray, J. Urquhart, and X. Lambin. 2011. Turning back the tide of American mink invasion at an unprecedented scale through community participation and adaptive management. Biological Conservation 144:575-583.

Buckland, S. T., D. R. Anderson, K. P. Burnham, and J. L. Laake. 1993. Distance sampling: estimating abundance of biological populations. Chapman and Hall, London, United Kingdom.

Burnham, K. P., and D. R. Anderson. 2002. Model selection and multimodel inference: a practical information-theoretic approach. Springer, New York, New York, USA.

Byrom, A. E. 2002. Dispersal and survival of juvenile feral ferrets Mustela furo in New Zealand. Journal of Applied Ecology 39:67-78.

Chamaillé-Jammes, S., H. Fritz, M. Valeix, F. Murindagomo, and J. Clobert. 2008. Resource variability, aggregation and direct density dependence in an open context: the local regulation of an African elephant population. Journal of Animal Ecology 77:135-144.

Cooley, H. S., R. B. Wielgus, G. M. Koehler, H. S. Robinson, and B. T. Maletzke. 2009. Does hunting regulate cougar populations? A test of the compensatory mortality hypothesis. Ecology 90:2913-2921.

Fletcher, K., N. J. Aebischer, D. Baines, R. Foster, and A. N. Hoodless. 2010. Changes in breeding success and abundance of ground-nesting moorland birds in relation to the experimental deployment of legal predator control. Journal of Applied Ecology 47:263-272.

Goodrich, J., and S. Buskirk. 1995. Control of abundant native vertebrates for conservation of endangered species. Conservation Biology 9:13571364.

Gosselink, T. E., K. A. Piccolo, T. R. Deelen, R. E. Warner, and P. C. Mankin. 2010. Natal dispersal and philopatry of red foxes in urban and agricultural areas of Illinois. Journal of Wildlife Management 74:12041217.

Harding, E. K., D. F. Doak, and J. D. Albertson. 2001. Evaluating the effectiveness of predator control: the non-native red fox as a case study. Conservation Biology 15:1114-1122.

Herrando-Pérez, S., S. Delean, B. W. Brook, and C. J. A. Bradshaw. 2012. Decoupling of component and ensemble density feedbacks in birds and mammals. Ecology 93:1728-1740.

Hewson, R. 1986. Distribution and density of fox breeding dens and the effects of management. Journal of Applied Ecology 23:531-538. 
Heydon, M., and J. Reynolds. 2000. Demography of rural foxes (Vulpes vulpes) in relation to cull intensity in three contrasting regions of Britain. Journal of Zoology 251:265-276.

Hone, J. 1999. On rate of increase (r): patterns of variation in Australian mammals and the implications for wildlife management. Journal of Applied Ecology 36:709-718.

Lebreton, J.-D. 2005. Dynamical and statistical models for exploited populations. Australian \& New Zealand Journal of Statistics 47: 49-63.

Loveridge, A., A. Searle, F. Murindagomo, and D. Macdonald. 2007. The impact of sport-hunting on the population dynamics of an African lion population in a protected area. Biological Conservation 134: 548-558.

Macdonald, D., and P. Johnson. 1996. The impact of sport hunting: a case study. The exploitation of mammal populations. Springer, Dordrecht, Netherlands.

Marques, T., L. Thomas, S. G. Fancy, and S. T. Buckland. 2007. Improving estimates of bird density using multiple-covariate distance sampling. Auk 124:1229-1243.

Newsome, T. M., M. S. Crowther, and C. R. Dickman. 2014. Rapid recolonisation by the European red fox: how effective are uncoordinated and isolated control programs. European Journal of Wildlife Research 60:749-757.

Novaro, A. J., M. C. Funes, and R. S. Walker. 2005. An empirical test of source-sink dynamics induced by hunting. Journal of Applied Ecology 42:910-920.

O’Mahony, D., X. Lambin, J. L. MacKinnon, and C. F. Coles. 1999. Fox predation on cyclic field vole populations in Britain. Ecography 22:575581.

Péron, G. 2013. Compensation and additivity of anthropogenic mortality: life-history effects and review of methods. Journal of Animal Ecology 82:408-417.

Reynolds, J. C., S. M. Richardson, B. J. E. Rodgers, and O. R. Rodgers. 2013. Effective control of non-native American mink by strategic trapping in a river catchment in mainland Britain. Journal of Wildlife Management 77:545-554.
Ruette, S., and M. Albaret. 2011. Reproduction of the red fox Vulpes vulpes in western France: does staining improve estimation of litter size from placental scar counts. European Journal of Wildlife Research 57:555-564.

Ruette, S., P. Stahl, and M. Albaret. 2003. Applying distance-sampling methods to spotlight counts of red foxes. Journal of Applied Ecology 40:32-43.

Rushton, S. P., M. D. F. Shirley, D. W. Macdonald, and J. C. Reynolds. 2006. Effects of culling fox populations at the landscape scale: a spatially explicit population modeling approach. Journal of Wildlife Management 70:1102-1110

Saunders, G. R., M. N. Gentle, and C. R. Dickman. 2010. The impacts and management of foxes Vulpes vulpes in Australia. Mammal Review 40:181211.

Servanty, S., J.-M. Gaillard, F. Ronchi, S. Focardi, É. Baubet, and O. Gimenez. 2011. Influence of harvesting pressure on demographic tactics: implications for wildlife management. Journal of Applied Ecology 48:835843.

Skalski, J., K. Ryding, and J. Millspaugh. 2005. Wildlife demography: analysis of sex, age, and count data. Elsevier-Academic Press, San Diego, California, USA.

Sutherland, W. J., A. S. Pullin, P. M. Dolman, and T. M. Knight. 2004. The need for evidence-based conservation. Trends in Ecology \& Evolution 19:305-308.

Trewhella, W., S. Harris, and F. McAllister. 1988. Dispersal distance, home-range size and population density in the red fox (Vulpes vulpes): a quantitative analysis. Journal of Applied Ecology 25:423-435.

Walsh, J. C., K. A. Wilson, J. Benshemesh, and H. P. Possingham. 2012. Unexpected outcomes of invasive predator control: the importance of evaluating conservation management actions. Animal Conservation 15:319-328.

Zuur, A. F., E. N. Ieno, N. J. Walker, A. A. Saveliev, and G. M. Smith. 2009. Mixed effects models and extensions in ecology with R. Springer, New York, New York, USA 